\title{
Preoperative multidetector computed tomograpy angiography for planning of minimally invasive robotic mitral valve surgery: Impact on decision making
}

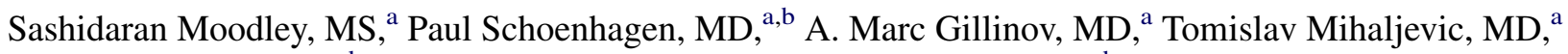 \\ Scott D. Flamm, MD, ${ }^{\mathrm{a}, \mathrm{b}}$ Brian P. Griffin, MD, ${ }^{\mathrm{a}}$ and Milind Y. Desai, MD ${ }^{\mathrm{a}, \mathrm{b}}$
}

\begin{abstract}
Background: Minimally invasive mitral valve (MV) surgeries (ie, right thoracotomy and robotic approaches) are preferred for degenerative mitral regurgitation because these procedures result in reduced surgical trauma and recovery time. However, because of peripheral cardiopulmonary bypass, there is risk of embolic complications. We sought to use the strengths of 3-dimensional multidetector computed tomography (MDCT) in assessing aortoiliac atherosclerosis and mitral annular calcification (MAC) and its influence on decision for approach in MV surgery.
\end{abstract}

\begin{abstract}
Methods: We included 141 patients with isolated grade 3 or $4+$ mitral regurgitation who underwent contrastenhanced MDCT of the chest, abdomen, and pelvis. Aortoiliac atherosclerosis was measured as circumferentiality $(0=$ none, $1=$ less than one third, $2=$ one third to two thirds, and $3=$ more than two thirds $)$ and thickness $(0=$ none or $<1 \mathrm{~mm}, 1=1$ to $2.9 \mathrm{~mm}, 2=3$ to $5 \mathrm{~mm}$, and $3=>5 \mathrm{~mm})$. Significant atherosclerosis was defined as circumferentiality score $\geq 1$ and/or thickness score $\geq 1$. Circumferentiality of MAC was also measured in a similar manner. Change in surgical approach was considered if a full/partial sternotomy was performed or surgical procedure was cancelled.
\end{abstract}

Results: One hundred eleven (79\%) patients (mean age, $54 \pm 11$ years; $67 \%$ men) underwent minimally invasive MV repair, whereas 30 patients ( $21 \%$ ) had surgical approach changed (1 surgical cancellation). Of 111 patients who underwent minimally invasive repair, $4(3.6 \%)$ patients had significant atherosclerosis/MAC, whereas $26(87 \%)$ patients had evidence of significant atherosclerosis/MAC in the changed approach group.

Conclusions: In patients undergoing minimally invasive MV surgery, there is a strong association between presence of significant aortoiliac atherosclerosis, as determined by MDCT and/or MAC and change in surgical approach. (J Thorac Cardiovasc Surg 2013;146:262-8)

f Supplemental material is available online.

Myxomatous mitral valve (MV) disease is a common valve abnormality often resulting in severe mitral regurgitation (MR) with a natural history that is associated with significant morbidity and mortality. ${ }^{1-3}$ Current clinical guidelines recommend surgical correction for symptomatic patients, but also for asymptomatic patients with various associated imaging/clinical characteristics. ${ }^{4}$ From a treatment standpoint, conventional, median sternotomy-based

From the Heart and Vascular Institute ${ }^{\mathrm{a}}$ and Imaging Institute, ${ }^{\mathrm{b}}$ Cleveland Clinic, Cleveland, Ohio.

Disclosures: Authors have nothing to disclose with regard to commercial support.

Presented as a poster at the American College of Cardiology 61st Annual Scientific Session \& Expo, Chicago, Illinois, March 24-17, 2012.

Received for publication March 8, 2012; revisions received May 31, 2012; accepted for publication June 18, 2012; available ahead of print July 27, 2012.

Address for reprints: Milind Y. Desai, MD, Tomsich Department of Cardiovascular Medicine, Heart and Vascular Institute, Cleveland Clinic, 9500 Euclid Ave, Desk

J1-5, Cleveland, OH 44195 (E-mail: desaim2@ccf.org).

$0022-5223 / \$ 36.00$

Copyright (C) 2013 by The American Association for Thoracic Surgery

http://dx.doi.org/10.1016/j.jtcvs.2012.06.052 surgical approaches yield excellent short- and long-term results. ${ }^{5-7}$ More recently, less invasive approaches have been introduced, including right-anterolateral thoracotomy through a small incision and robotic MV repair, to reduce surgical trauma, incision size, and postoperative recovery time with excellent early and intermediate-term results. ${ }^{8-11}$ However, limited intraoperative exposure requires extensive modification of surgical technique. As a result, selection of patients for minimally invasive procedures depends on careful preoperative planning, based on history, clinical examination, and multimodality imaging. ${ }^{12}$ Mitral annular calcification (MAC) and ileofemoral arterial access are typically assessed by echocardiography and invasive angiography, respectively. However, the full extent of MAC and atherosclerosis are not well identified with these modalities.

The incremental value of pre-operative imaging with multidetector computed tomography (MDCT) has been previously demonstrated. ${ }^{13,14} \mathrm{~A}$ particular strength of MDCT is the assessment of vascular wall anatomy, especially calcification. The identification and quantification of these changes in the vessel wall without luminal stenosis is the strength of 3-dimensional MDCT. Although the 


$$
\begin{aligned}
& \text { Abbreviations and Acronyms } \\
& \begin{aligned}
\mathrm{CT} & =\text { computed tomography } \\
\mathrm{ECG} & =\text { electrocardiogram } \\
\mathrm{MDCT} & =\text { multidetector computed tomography } \\
\mathrm{MR} & =\text { mitral regurgitation } \\
\mathrm{MV} & =\text { mitral valve }
\end{aligned}
\end{aligned}
$$

significance of these changes is incompletely understood, their potential role in embolization with reversed aortic flow should not be underestimated. However, it remains unclear if imaging identifies individual lesions with increased risk for embolic events or overall patient risk. Based on these data, thoracoabdominal aortic and iliac MDCT angiography is routinely performed as part of the preoperative assessment of our patients referred for robotically assisted MV repair. This study evaluates the influence of preoperative MDCT angiography in decision making regarding the operative approach (minimally invasive vs standard surgical) in patients undergoing minimally invasive MV repair.

\section{METHODS}

Our retrospective observational study included consecutive patients with grade $3+\mathrm{MR}$ who were referred to our center for possible minimally invasive MV repair using a robotic approach. Patients underwent a comprehensive preoperative workup that included clinical evaluation, electrocardiogram, routine laboratory testing, echocardiography, and coronary angiography. In addition, all patients underwent contrast-enhanced MDCT of chest, abdomen, and pelvis. We excluded the following groups of patient from our study population: patients with noncontrast computed tomography (CT) or contraindications to iodinated contrast administration (allergy or renal dysfunction), patients with additional significant valvular lesions ( $\geq 1$ valvular regurgitation other than MR, and patients with $>1$ mitral stenosis), resting atrial fibrillation on current electrocardiogram (ECG), known severe obstructive $(>50 \%)$ epicardial coronary artery disease, history of prior cardiothoracic surgeries (coronary bypass grafting, valvular surgeries, cardiac transplantation, or aortic surgeries), and known prior severe peripheral arterial disease.

The final study population consisted of 141 patients who met the inclusion/exclusion criteria. Standard demographic and clinical data were recorded. Preoperative New York Heart Association functional class was also recorded. The study was performed after appropriate institutional review board approval and waiver of individual informed consent.

The primary endpoint in this study was change in the intended surgical procedure. Because these patients were specifically referred for minimally invasive robotic surgery, they were preemptively screened and considered at low risk. A change in intended surgical approach was defined as a recommendation of a conventional full/partial sternotomy or cancellation of surgical procedure (because of perceived increased risk related to robotic surgery). The decision to change the surgical approach was made by the surgeon after assessment of the individual patient's MDCT findings. In those patients who underwent MV surgery (robotic or conventional approach), postoperative in-hospital length of stay and 30-day events (including death, stroke, and postoperative atrial fibrillation) were recorded as secondary endpoints.

\section{ECG Data}

All patients underwent comprehensive ECG using commercially available instruments (HDI 5000, Philips Medical Systems, NA, Bothell, Wash, and Acuson Sequoia, Siemens Medical Solutions USA, Inc, Malvern, Pa) as part of standard preoperative workup. Left atrial volumes, left ventricular ejection fraction, and dimensions were measured according to previously described criteria. ${ }^{15}$ Degree of resting MR was assessed by color Doppler and quantified according to multiple established criteria on a scale of 0 to $4+(0=$ none, $1+=$ mild, $2+=$ moderate, $3+=$ moderately severe and $4+=$ severe). ${ }^{16}$ In addition, degree of MR and left ventricular ejection fraction were recorded on predischarge resting ECG.

\section{MDCT Data}

All patients received scanning on a standard clinical MDCT scanner (Philips Brilliance 256-slice scanner, Best, The Netherlands) after administration of an iodinated contrast agent $(130 \mathrm{~mL}$ Ultravist 370 , Bayer Healthcare, Berlin, Germany) at $3.5 \mathrm{~mL} / \mathrm{second}$. The scans were acquired in 2 parts: An initial prospective ECG-triggered axial scan from the level of the thoracic inlet to the level of the diaphragm (after administration of $80 \mathrm{cc}$ contrast) followed by a second non-ECG gated spiral acquisition of the abdomen and pelvis, extending from the diaphragm to the midthigh (with an additional administration of $50 \mathrm{cc}$ iodinated contrast). The following parameters were applied: gantry rotation time $=270 \mathrm{msec}$; patient-specific beam collimation $(96$ to $128 \times 0.625 \mathrm{~mm}$ ); tube voltage $=120 \mathrm{kVp}$; beam pitch $=0.625$ (for the spiral scan). Images were reconstructed at 3-mm slice thickness. Dose length product, as a measure of radiation dose $(\mathrm{mGy} \times \mathrm{cm})$, was recorded for all patients.

Subsequently, all images were loaded on a dedicated workstation (TeraRecon, San Francisco, Calif) for offline multiplanar 3-dimensional analysis. The investigator performing the MDCT analysis was blinded to each patient's clinical and operative status. Initially, the images were reconstructed along the centerline of the aorta and pelvic arteries using manual 3-dimensional reconstruction (Figure 1). Measurements were performed from true short-axis double oblique images, reconstructed orthogonal to the vessel centerline. The window center and level were adjusted to reduce the effect of calcium blooming on vessel measurements. The dimensions of the aorta were measured at the following levels: aortic root, midascending aorta, midaortic arch, proximal descending aorta, suprarenal aorta, and infrarenal aorta. The dimensions of the pelvic arteries were measured at the level of the bilateral common iliac arteries, external iliac arteries, and common femoral arteries. In addition, the location of aortic and pelvic arterial atherosclerosis was recorded. Atherosclerotic changes were characterized as obstructive (presence of $>50 \%$ luminal stenosis by visual assessment) or nonobstructive (absence of luminal stenosis by visual assessment). Finally, the extent of atherosclerosis was semiquantitatively measured as ${ }^{14}$ : circumferentiality $(0=$ none, $1=$ less than one-third circumference, 2 one-third to two-thirds circumference, and $3=$ more than two-thirds circumference) and thickness $(0=$ none or $<1 \mathrm{~mm}$, $1=1$ to $2.9 \mathrm{~mm}, 2=3$ to $5 \mathrm{~mm}$, and $3=>5 \mathrm{~mm}$ ). We added the circumferentiality and thickness score to generate an "atherosclerotic extent" score. In addition, atherosclerosis was classified as significant if circumferentiality score $>1$ and/or thickness score $\geq 1$ was identified in at least 1 vascular segment.

In addition, extent of MAC was recorded using short axis doubleoblique multiplanar reformatting of the heart at the level of mitral annulus/MV, after appropriate adjustment of the window to reduce calcium blooming (Figure E1). The following characteristics were recorded: maximal thickness in millimeters, measured from the leading anterior to the trailing posterior edge at its greatest width $(0=$ none, $1=<1 \mathrm{~mm}$, $2=1$ to $4 \mathrm{~mm}$ and $3=\geq 4 \mathrm{~mm}$; and circumferentiality $(0=$ none, $1=$ less than one-third circumference, $2=$ one-third to two-thirds circumference, and $3=$ more than two-thirds circumference). Significant MAC was defined as circumferentiality score $>1$ or thickness score $\geq 1$.

\section{Repair Technique}

The various surgical MV repair techniques (sternotomy, partial sternotomy, and minimally invasive robotic approach) at our institution have been 


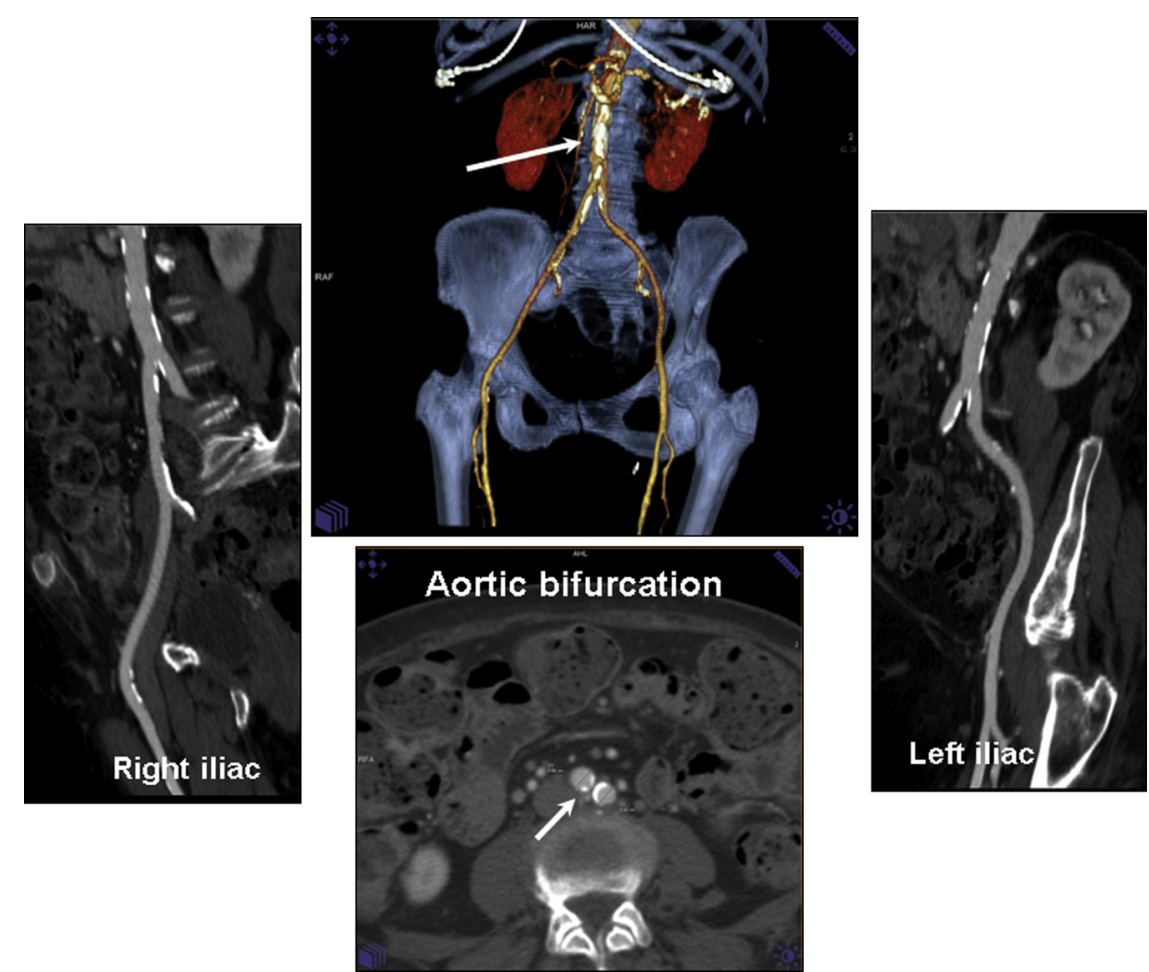

FIGURE 1. Three-dimensional reconstructions of multidetector computed tomography scans of the aorta in a patient being evaluated for mitral valve surgery. Top center, Volume-rendered reconstruction of the abdominal aorta and its pelvic branches reveal significant calcification near the aortic bifurcation (arrow). Right, Multiplanar reconstruction of the right iliac arteries. Left, Multiplanar reconstruction of the left iliac arteries. Bottom center, An axial image at the level of aortic bifurcation reveals partially circumferential calcific atherosclerosis.

described recently. ${ }^{11}$ Briefly, for robotic MV repair, cardiopulmonary bypass was established by cannulating the femoral artery and vein. After pericardiotomy, the ascending aorta was occluded with a transthoracic clamp or an endoballoon. The left arm of the robot was inserted through the third intercostal space near the anterior-axillary line and the right arm was inserted through the fifth intercostal space in the midaxillary line. A minithoracotomy for the working port was placed in the fourth intercostal space in the midaxillary line, and a dynamic left atrial retractor was placed in the midclavicular line. The details of MV repair have been published in detail elsewhere. ${ }^{11}$

\section{Statistics}

Baseline demographics, risk factors, and clinical variables were summarized for the group. Continuous variables are expressed as a mean \pm standard deviation. Categorical data are presented using percentage frequencies. Differences between groups were determined by using Student $t$ test or analysis of variance for continuous variables (Mann-Whitney $U$ test for nonparametric variables) and the $\chi^{2}$ test for categorical variables. In addition, logistic regression analysis was performed to test the association between dependent variable (primary endpoint; that is, change in surgical approach) and various potential predictors. For multivariable regression analysis, predictors with $P<.10$ on univariable analysis were included. Data assembly and statistical analysis was performed with SPSS version 19 (IBM Corp, Armonk, NY).

\section{RESULTS}

The baseline clinical characteristics of the study population are shown in Table 1. All patients met New York Heart Association Class I or II functional criteria for MV repair.
No patient had glomerular filtration rate $<60 \mathrm{~mL} / \mathrm{kg} / 1.73 \mathrm{~m}^{2}$. No patient in the study population had obstructive coronary atherosclerosis. The baseline ECG and MDCT characteristics of the study population are shown in Table 2 . Left ventricular ejection fraction was preserved $(\geq 55 \%)$ in 134 $(95 \%)$ patients. In the remaining $7(5 \%)$ patients, it was between $45 \%$ and $55 \%$. In $54(39 \%)$ patients, the left ventricular end-diastolic dimensions were $>5.5 \mathrm{~cm}$. The average time between MDCT and invasive coronary angiography was at least 24 hours. The average time between invasive coronary angiography and surgery was 48 hours. No patient developed contrast-induced nephropathy in the study. No patient had an interruption of the inferior vena cava. No patient had significant obstructive ( $>50 \%$ stenosis) disease of the aorta or iliofemoral vasculature. Approximately 1 in 5 patients displayed evidence of significant atherosclerosis of the aorta or its pelvic branches. The mean minimal luminal diameter of pelvic vasculature was similar in the groups that underwent minimally invasive MV repair versus those that had sternotomy $(8.2 \pm 1.2 \mathrm{~mm}$ vs $7.8 \pm 2 \mathrm{~mm} ; P=.21)$. Altogether, 30 patients $(21 \%)$ had either significant atherosclerosis or MAC.

\section{OUTCOMES}

Of the study population, $111(79 \%)$ underwent minimally invasive robotic MV repair and all underwent the 
TABLE 1. Baseline clinical characteristics of the study population

\begin{tabular}{|c|c|c|c|c|}
\hline Variable & $\begin{array}{l}\text { Total group } \\
(n=141)\end{array}$ & $\begin{array}{l}\text { Robotic surgery group } \\
\quad(\mathbf{n}=\mathbf{1 1 1})\end{array}$ & $\begin{array}{l}\text { Changed surgery group } \\
\qquad(\mathbf{n}=\mathbf{3 0})\end{array}$ & $P$ value \\
\hline Age $(y)$ & $54 \pm 11$ & $51 \pm 11$ & $63 \pm 11$ & $<.001$ \\
\hline Men & $94(67 \%)$ & $79(71 \%)$ & $15(50)$ & .03 \\
\hline Body surface area $\left(\mathrm{m}^{2}\right)$ & $1.96 \pm 0.23$ & $1.98 \pm 0.23$ & $1.89 \pm 0.22$ & .07 \\
\hline Glomerular filtration rate $\left(\mathrm{mL} / \mathrm{min} / 1.73 \mathrm{~m}^{2}\right)$ & $86 \pm 16$ & $87 \pm 16$ & $82 \pm 15$ & .2 \\
\hline Hypertension & $42(30 \%)$ & $28(25 \%)$ & $14(47 \%)$ & .02 \\
\hline Smoking (current or former) & $51(36 \%)$ & $34(31 \%)$ & $17(57 \%)$ & .03 \\
\hline Diabetes mellitus & $1(0.7 \%)$ & 0 & 1 & \\
\hline Prior stroke & $5(4 \%)$ & $4(4 \%)$ & $1(3 \%)$ & .9 \\
\hline Preoperative atrial fibrillation & $22(16 \%)$ & $15(14 \%)$ & $7(23 \%)$ & .2 \\
\hline \multicolumn{5}{|l|}{ NYHA class } \\
\hline I & $65(46 \%)$ & $54(49 \%)$ & $11(37 \%)$ & .12 \\
\hline II & $59(42 \%)$ & $47(42 \%)$ & $12(40 \%)$ & \\
\hline III & $17(12 \%)$ & $10(9 \%)$ & $7(23 \%)$ & \\
\hline IV & 0 & 0 & 0 & \\
\hline
\end{tabular}

Data presented as mean \pm standard deviation or no. (\%). NYHA, New York Heart Association.

procedure successfully. The remainder of the 29 patients $(21 \%)$ underwent an alternative surgical approach (partial or a full sternotomy). Only 1 patient had the surgical procedure entirely cancelled following the workup (this was due to severe comorbidities). Of the 28 patients with significant atherosclerosis, $26(93 \%)$ had a change in surgical approach to a sternotomy-based approach, whereas 2 proceeded with robotic MV repair $(P<.001)$. Similarly, of

TABLE 2. Imaging characteristics of the study population

\begin{tabular}{|c|c|c|c|c|}
\hline Variable & $\begin{array}{l}\text { Total group } \\
(\mathrm{n}=141)\end{array}$ & $\begin{array}{l}\text { Robotic group } \\
\quad(\mathbf{n}=\mathbf{1 1 1})\end{array}$ & $\begin{array}{l}\text { Changed surgery group } \\
\qquad(\mathrm{n}=\mathbf{3 0})\end{array}$ & $P$ value \\
\hline \multicolumn{5}{|l|}{ Echocardiography } \\
\hline $\mathrm{MR}(\geq \mathrm{III}+)$ & $141(100 \%)$ & $111(100 \%)$ & $30(100 \%)$ & .9 \\
\hline LA volume index $\left(\mathrm{mL} / \mathrm{m}^{2}\right)$ & $31 \pm 14$ & $30 \pm 13$ & $33 \pm 17$ & .2 \\
\hline LV-EDV index $\left(\mathrm{cm} / \mathrm{m}^{2}\right)$ & $2.7 \pm 0.4$ & $2.7 \pm 0.4$ & $2.8 \pm 0.5$ & .6 \\
\hline LV-ESV index $\left(\mathrm{cm} / \mathrm{m}^{2}\right)$ & $1.7 \pm 0.3$ & $1.7 \pm 0.3$ & $1.8 \pm 0.4$ & .2 \\
\hline LV ejection fraction $(\%)$ & $59 \pm 5$ & $59 \pm 5$ & $59 \pm 5$ & .9 \\
\hline RVSP & $36 \pm 13$ & $36 \pm 12$ & $39 \pm 13$ & .2 \\
\hline \multicolumn{5}{|l|}{ Multidetector computed tomography } \\
\hline Contrast dose $(\mathrm{mL})$ & $130 \pm 8$ & $130 \pm 10$ & $130 \pm 2$ & .9 \\
\hline Significant MAC & $10(7 \%)$ & $2(2 \%)$ & $8(27 \%)$ & $<.001$ \\
\hline \multicolumn{5}{|l|}{ Aortic dimensions (mm) } \\
\hline Aortic root & $36 \pm 4$ & $36 \pm 4$ & $35 \pm 4$ & 4 \\
\hline Midascending & $31 \pm 4$ & $31 \pm 4$ & $32 \pm 4$ & .5 \\
\hline Aortic arch & $27 \pm 3$ & $27 \pm 3$ & $27 \pm 3$ & .9 \\
\hline Middescending & $22 \pm 2$ & $22 \pm 2$ & $23 \pm 2$ & .5 \\
\hline Suprarenal aorta & $19 \pm 2$ & $19 \pm 2$ & $19 \pm 3$ & .9 \\
\hline Midinfrarenal & $17 \pm 2$ & $17 \pm 2$ & $17 \pm 2$ & .9 \\
\hline Minimal luminal diameter of iliofemoral arteries (mm) & $8 \pm 2$ & $8 \pm 2$ & $7.8 \pm 1.2$ & .2 \\
\hline \multicolumn{5}{|l|}{ Distribution of any aortic atherosclerosis } \\
\hline Ascending & $1(2 \%)$ & $1(1 \%)$ & 0 & \\
\hline Arch & $3(6 \%)$ & 0 & $3(10 \%)$ & \\
\hline Descending & $5(10 \%)$ & $1(1 \%)$ & $4(13 \%)$ & $<.001$ \\
\hline Suprarenal & $2(4 \%)$ & 0 & $2(7 \%)$ & \\
\hline Infrarenal & $20(38 \%)$ & $12(11 \%)$ & $8(27 \%)$ & \\
\hline Iliofemoral & $22(42 \%)$ & $13(12 \%)$ & $9(30 \%)$ & \\
\hline Atherosclerotic extent score & $1.1 \pm 1.6$ & $0.5 \pm 0.9$ & $3.4 \pm 1.8$ & $<.001$ \\
\hline Significant aortoiliac atherosclerosis & $28(20 \%)$ & $2(2 \%)$ & $26(87 \%)$ & $<.001$ \\
\hline
\end{tabular}


10 patients with significant MAC, $8(80 \%)$ had a change in surgical approach, whereas $2 \operatorname{did} \operatorname{not}(P<.001)$. Overall, 30 patients had significant atherosclerosis and/or MAC, of which $26(87 \%)$ had a change in surgical approach, whereas 4 did not $(P<.001)$. The association between MDCT findings and change in surgical approach is shown in Figure 2. Table 3 shows various factors that were associated with a change in surgical approach in the study population. Presence of significant atherosclerosis/MAC and increasing age were associated with change in surgery from minimally invasive to sternotomy-based approach. The surgical outcomes (secondary endpoints) of the study population are shown in Table E1. In our study population, there were no 30-day deaths in the robotic MV repair group; 1 patient in the standard sternotomy group died during the postoperative period as a result of multiorgan failure. One patient in the robotic MV repair group developed left sided weakness and speech problems on Postoperative Day 1. All his testing, including neurologic tomography and invasive cerebral angiography, were negative. His weakness resolved on Postoperative Day 3 and he was discharged without residual effects. It was presumed to be embolic in nature. There were no major bleeding/vascular complications requiring prolonged hospital stay. The average length of stay was significantly shorter for the robotic group $(4.2 \pm 1.1$ days $)$, compared with the sternotomy group $(6.3 \pm 3.6$ days; $P<.001)$.

\section{DISCUSSION}

Our data demonstrate that in $21 \%$ of asymptomatic or mildly symptomatic patients with severe MR referred for robotic MV repair, a change to conventional surgical approach occurred after comprehensive clinical evaluation and MDCT angiography of the chest, abdomen, and pelvis revealed significant subclinical aortoiliac atherosclerosis and/or MAC. These data could potentially be

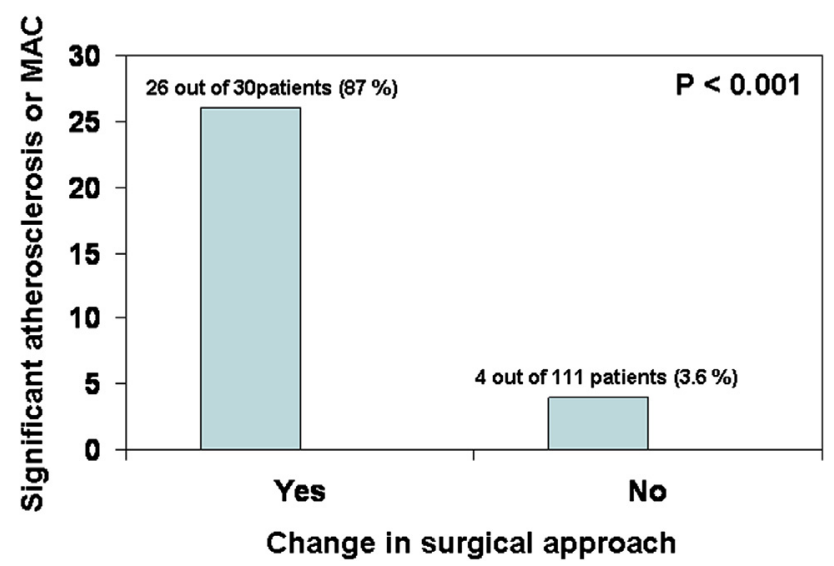

FIGURE 2. Association between change in surgical approach and presence of significant aortoiliac atherosclerosis and mitral annular calcification $(M A C)$.
TABLE 3. Univariable and multivariable logistic regression analysis to assess predictors of change in surgical approach for mitral valve repair

\begin{tabular}{lccccc}
\hline & \multicolumn{2}{c}{ Univariable } & & \multicolumn{2}{c}{ Multivariable } \\
\cline { 2 - 3 } \multicolumn{1}{c}{ Variable } & Wald's & $\boldsymbol{P}$ & & Wald's & $\boldsymbol{P}$ \\
statistic & value & statistic & value \\
\hline Age & 18.06 & $<.001$ & 5.91 & .02 \\
Sex & 4.61 & .03 & & \\
NYHA class & 3.41 & .07 & & \\
Hypertension & 5.00 & .03 & & \\
Smoking history & 7.74 & .005 & & \\
Body mass index & 0.37 & .55 & & \\
LV ejection fraction & 0.89 & .35 & & \\
Indexed LA volume & 1.61 & .21 & & \\
Indexed LV end-diastolic & 0.29 & .59 & & \\
$\quad$ diameter & & & & \\
Significant atherosclerosis & 48.6 & $<.0001$ & 29.38 & $<.0001$ \\
$\quad$ or MAC & & & & \\
Minimal luminal caliber of & 1.51 & .22 & & \\
$\quad$ pelvic arteries & & & & \\
\hline $\begin{array}{l}N Y H A, \text { New York Heart Association; } L V, \text { left ventricle; } L A, \text { left atrium; } M A C, \text { mitral } \\
\text { annular calcification. }\end{array}$ & & & &
\end{tabular}

important to understand the need for preoperative imaging in the context of novel robotic approaches to MV repair.

The limited intraoperative exposure of the operative field requires extensive modification of surgical technique, including the approach to cardiopulmonary bypass and the valve procedure itself. Cardiopulmonary bypass is established in a retrograde fashion by cannulating the femoral artery and vein and occlusion of the ascending aorta with either an endoballoon or clamp. ${ }^{11}$ The blood flow in the iliac arteries and aorta is subsequently reversed for brain perfusion. In patients with aortoiliac atherosclerotic disease, peripheral cannulation and flow reversal has been shown to be associated with an increases risk of embolic cerebrovascular complications. ${ }^{17}$ Hence, it would be important to understand the atherosclerotic burden in patients being considered for retrograde brain perfusion during cardiac surgery. However, the atherosclerotic disease burden in patients referred for minimally invasive MV surgery is unknown. One might argue that in a relatively young population without significant comorbidities, prevalence of atherosclerosis would be very low. However, in our study, approximately $20 \%$ of patients had evidence of significant (albeit nonobstructive) atherosclerosis of the thoracoabdominal aorta or its iliofemoral branches, with a predominance of the infrarenal aorta or pelvic arteries. Importantly, the minimal luminal caliber of pelvic arteries was maintained, and there was no association between the pelvic arterial luminal caliber and selection of surgical approach.

The identification and quantification of these changes in the vessel wall without luminal stenosis is the strength of 
3-dimensional, cross-sectional imaging with contrastenhanced MDCT angiography. In contrast, conventional angiography lacks sensitivity for vessel wall changes because of outward vessel wall remodeling. ${ }^{18}$ Although the significance of these changes is incompletely understood, their potential role in embolization with reversed aortic flow should not be underestimated. However, it remains unclear if imaging identifies individual lesions with increased risk for embolic events or overall patient risk. In fact, recent research supports the concept that atherosclerotic disease burden is a marker for dismal outcome. ${ }^{14,19}$ Future studies will need to define the role of noninvasive imaging. Similarly, extent and location of MAC correlates with complexity of repair. Therefore patients with extensive MAC are currently not considered optimal candidates for robotic surgery. Identification, precise localization, and quantification of valvular calcification is a strength of CT and has been demonstrated in valvular disease. ${ }^{20}$ One can argue that a noncontrast CT could also be a viable option for assessment of MAC and aortoiliac atherosclerosis. However, the ability of contrast enhancement to assess luminal stenosis (in case of a heavily calcific lesion) is far superior than that of a noncontrast CT. Furthermore, these are relatively young patients with preserved renal function where the likelihood of developing renal failure is extremely low. One can also make an argument for using transesophageal echocardiography and femoral ultrasound to evaluate such patients, instead of MDCT. However, doing transesophageal echocardiography preoperatively in all patients would unnecessarily add a semi-invasive test with sedation. In most cases, an adequate quality transthoracic echo is deemed sufficient. All patients undergo intraoperative transesophageal echocardiography, but in our opinion, a decision regarding the appropriate approach should not be made in an operating room after intraoperative transesophageal echocardiography, because it would provide a logistic problem of equipment (eg, sternotomy vs robotic equipment) as well as operating room time. Femoral ultrasound, although an attractive option is not the best at assessing nonobstructive calcific/noncalcific lesions. Its best utility is in assessment of flow-limiting lesions. As shown in our study, there were no flow-limiting lesions.

One might argue that use of MDCT could play a role in evaluating older individuals (or younger patients with risk factors for atherosclerosis) for subclinical atherosclerosis before robotic MV repair. Indeed, in our study patients who underwent the conventional surgical approach were older with additional comorbidities, along with a higher rate of postoperative atrial fibrillation and length of stay. It further demonstrates the potential incremental prognostic value of preoperative imaging with MDCT angiography, which has previously been demonstrated in different patient populations. ${ }^{13,14}$ A particular strength of MDCT in preoperative imaging is the assessment of cardiovascular calcification and vascular wall anatomy, in part because of the ability to reconstruct the 3-D data along unlimited planes and the vessel centerline after image acquisition.

Because the natural history of severe myxomatous MR is associated with significant morbidity and mortality, guidelines recommend surgical correction for asymptomatic patients with severe regurgitation and left ventricular dilatation. ${ }^{4}$ Novel, less invasive surgical approaches, including limited mini right-anterolateral thoracotomy and robotic MV repair, are particularly attractive for asymptomatic or mildly symptomatic patients because of the reduced surgical trauma, incision size, and postoperative recovery time..$^{8-11,21,22}$ However, in these patients, conventional, median sternotomy-based surgical approaches are well established and yield excellent short- and long-term results, which sets an extremely high standard for novel procedures. $^{5-7}$ It is therefore critical to identify potential contraindications for less invasive surgery before the procedure, to preserve the safety and quality achieved by surgery through complete sternotomy.

\section{Strengths and Limitations}

This was an observational study where the information obtained on MDCT was used for clinical decision making, particularly selection of the surgical approach. Hence, one might argue that the significant association between MDCT findings and change in surgical approach would have been expected. The use of MDCT angiography has to be weighed against the burden of nephrotoxicity and radiation exposure. With state-of-the-art generation fast scanners and diligent use of aggressive radiation-reduction techniques, it is becoming less of an issue. ${ }^{23,24}$ Indeed, in our study, we used prospective-triggered axial scanning for the thoracic portion of the study and nongated imaging through the abdomen and pelvis to achieve a mean radiation dose of $<10 \mathrm{mSeV}$. Newer-generation scanners have faster gantry rotation times, so the dose of iodinated contrast can be substantially reduced without notable compromise in image quality. There are currently no definitive guidelines for determining at what point, according to MDCT findings, robotic surgery should be avoided. The primary aim of our study was not to assess outcomes based on MDCT. The outcomes of isolated MV repair (by all approaches, be it full sternotomy, hemisternotomy, right thoracotomy, or robotic approach) performed at our institution are very good-approaching $0 \%$ mortality. As a result, we would need a large population with a very long follow-up to achieve any statistical significance. Future prospective studies, randomizing the approach for a given severity of aortoiliac atherosclerosis and/or MAC as determined by MDCT, would better evaluate the benefits to preoperative imaging and its costeffectiveness. Because of the lack of a control group it remains unclear if preoperative imaging is associated with a reduction in complications such as stroke. We also did not examine the potential role of the preoperative MDCT 
for assessment of coronary anatomy, which could be acquired at the same time with some changes to the acquisition protocol. That could have the added potential utility of avoiding an invasive coronary angiogram.

\section{CONCLUSIONS}

Our data demonstrates that subclinical aortic atherosclerotic disease and MAC is frequently observed in patients evaluated for robotic MV surgery. Preoperative MDCT with aortoiliac angiography could enable precise assessment of the extent of aortoiliac atherosclerosis and MAC, especially in older patients (or those with increased risk for atherosclerosis) and these findings are associated with a recommended change in surgical approach from minimally invasive robotic surgery to standard sternotomybased surgery. Future studies are needed to examine the influence of MDCT angiography on decision making and its cost-effectiveness in this population.

\section{References}

1. Ling LH, Enriquez-Sarano M, Seward JB, Tajik AJ, SCAF HV, Bailey KR, et al Clinical outcome of mitral regurgitation due to flail leaflet. N Engl J Med. 1996; 335:1417-23.

2. Rosenhek R, Rader F, Klaar U, Gabriel H, Krejc M, Kalbeck D, et al. Outcome of watchful waiting in asymptomatic severe mitral regurgitation. Circulation. 2006; 113:2238-44.

3. Tribouilloy CM, Enriquez-Sarano M, Schaff HV, Orszulak TA, Bailey KR, Tajik AJ, et al. Impact of preoperative symptoms on survival after surgical correction of organic mitral regurgitation: rationale for optimizing surgical indications. Circulation. 1999;99:400-5.

4. Bonow RO, Carabello BA, Chatterjee K, de Leon AC Jr, Faxon DP, Freed MD, et al. ACC/AHA 2006 guidelines for the management of patients with valvular heart disease: a report of the American College of Cardiology/American Heart Association Task Force on Practice Guidelines (Writing Committee to revise the 1998 guidelines for the management of patients with valvular heart disease) developed in collaboration with the Society of Cardiovascular Anesthesiologists endorsed by the Society for Cardiovascular Angiography and Interventions and the Society of Thoracic Surgeons. J Am Coll Cardiol. 2006;48:e1-148.

5. Braunberger E, Deloche A, Berrebi A, Abdallah F, Celestin JA, Meimoun P, et al. Very long-term results (more than 20 years) of valve repair with carpentier's techniques in nonrheumatic mitral valve insufficiency. Circulation. 2001;104: I8-11.

6. Mohty D, Orszulak TA, Schaff HV, Avierinos JF, Tajik JA, Enriquez-Sarano M. Very long-term survival and durability of mitral valve repair for mitral valve prolapse. Circulation. 2001;104:I1-7.

7. Gillinov AM, Blackstone EH, Nowicki ER, Slisatkorn W, Al-Dossari G, George KM, et al. Valve repair versus valve replacement for degenerative mitral valve disease. J Thorac Cardiovasc Surg. 2008;135:885-93, e1-2.
8. Modi P, Rodriguez E, Hargrove WC 3rd, Hassan A, Szeto WY, Chitwood WR Jr. Minimally invasive video-assisted mitral valve surgery: a 12-year, 2-center experience in 1178 patients. $J$ Thorac Cardiovasc Surg. 2009;137:1481-7.

9. McClure RS, Cohn LH, Wiegerinck E, Couper GS, Aranki SF, Bolman RM 3rd, et al. Early and late outcomes in minimally invasive mitral valve repair: an eleven-year experience in 707 patients. J Thorac Cardiovasc Surg. 2009;137: $70-5$.

10. Svensson LG, Atik FA, Cosgrove DM, Blackstone EH, Rajeswaran J, Krishnaswamy G, et al. Minimally invasive versus conventional mitral valve surgery: a propensity-matched comparison. $J$ Thorac Cardiovasc Surg. 2010;139: 926-32, e1-2.

11. Mihaljevic T, Jarrett CM, Gillinov AM, Williams SJ, DeVilliers PA, Stewart WJ, et al. Robotic repair of posterior mitral valve prolapse versus conventional approaches: potential realized. J Thorac Cardiovasc Surg. 2011;141:72-80.e1-4.

12. Anderson CA, Kypson AP, Chitwood WR Jr. Robotic mitral surgery: current and future roles. Curr Opin Cardiol. 2008;23:117-20.

13. Kamdar AR, Meadows TA, Roselli EE, Gorodeski EZ, Curtin RJ, Sabik JF, et al. Multidetector computed tomographic angiography in planning of reoperative cardiothoracic surgery. Ann Thorac Surg. 2008;85:1239-45.

14. Kurra V, Lieber ML, Sola S, Kalahasti V, Hammer D, Gimple S, et al. Extent of thoracic aortic atheroma burden and long-term mortality after cardiothoracic surgery: a computed tomography study. JACC Cardiovasc Imaging. 2010;3:1020-9.

15. Lang RM, Bierig M, Devereux RB, Flachskamfp FA, Foster E, Pellikka PA, et al. Recommendations for chamber quantification: a report from the American Society of Echocardiography's Guidelines and Standards Committee and the Chamber Quantification Writing Group, developed in conjunction with the European Association of Echocardiography, a branch of the European Society of Cardiology. J Am Soc Echocardiogr. 2005;18:1440-63.

16. Zoghbi WA, Enriquez-Sarano M, Foster E, Grayburn PA, Kraft CD, Levine RA, et al. Recommendations for evaluation of the severity of native valvular regurgitation with two-dimensional and Doppler echocardiography. J Am Soc Echocardiogr. 2003;16:777-802.

17. Crooke GA, Schwartz CF, Ribakove GH, Ursomanno P, Gogoladze G, Culliford AT, et al. Retrograde arterial perfusion, not incision location, significantly increases the risk of stroke in reoperative mitral valve procedures. Ann Thorac Surg. 2010;89:723-9.

18. Schoenhagen P, Tuzcu EM, Stillman AE, Moliterno DJ, Halliburton SS, Kuzmiak SA, et al. Non-invasive assessment of plaque morphology and remodeling in mildly stenotic coronary segments: comparison of 16-slice computed tomography and intravascular ultrasound. Coron Artery Dis. 2003;14:459-62.

19. Takasu J, Katz R, Nasir K, Carr JJ, Wong N, Detrano R, et al. Relationships of thoracic aortic wall calcification to cardiovascular risk factors: the MultiEthnic Study of Atherosclerosis (MESA). Am Heart J. 2008;155:765-71.

20. Delgado V, Tops LF, Schuijf JD, de Roos A, Brugada J, Schalij MJ, et al. Assessment of mitral valve anatomy and geometry with multislice computed tomography. JACC Cardiovasc Imaging. 2009;2:556-65.

21. Ryan WH, Brinkman WT, Dewey TM, Mack MJ, Prince SL, Herbert MA. Mitral valve surgery: comparison of outcomes in matched sternotomy and port access groups. J Heart Valve Dis. 2010;19:51-8.

22. Chitwood WR Jr, Rodriguez E, Chu MW, et al. Robotic mitral valve repairs in 300 patients: a single-center experience. J Thorac Cardiovasc Surg. 2008;136: 436-41.

23. Halliburton SS, Schoenhagen P. Cardiovascular imaging with computed tomography: responsible steps to balancing diagnostic yield and radiation exposure. JACC Cardiovasc Imaging. 2010;3:536-40.

24. Earls JP, Leipsic J. Cardiac computed tomography technology and dosereduction strategies. Radiol Clin North Am. 2010;48:657-74. 


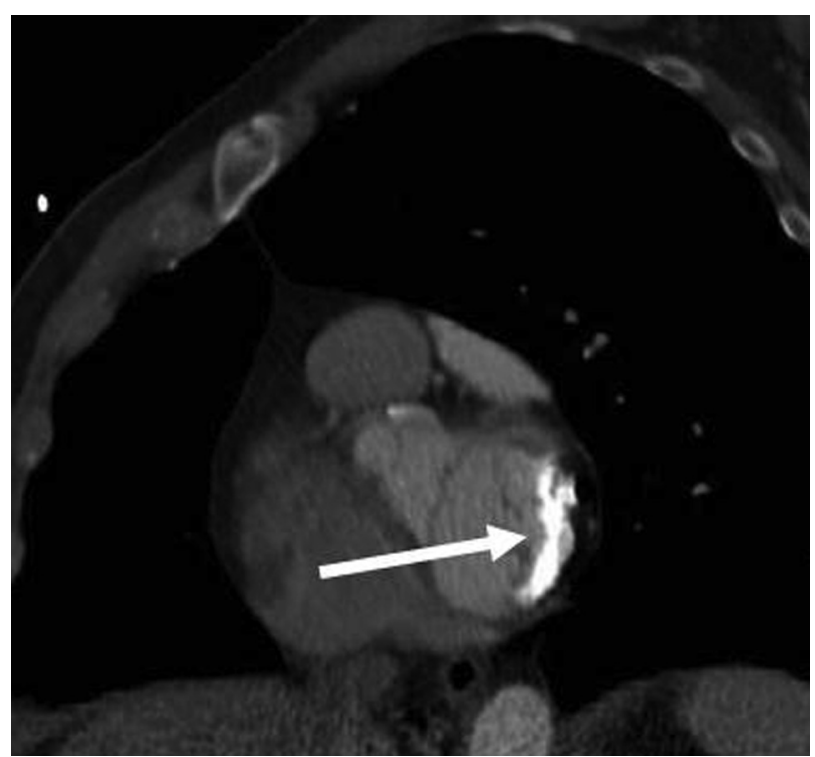

FIGURE E1. A multiplanar reformatted image at the level of the mitral valve reveals significant posterior annular calcification.

TABLE E1. Peri- and postoperative outcomes in the study population

\begin{tabular}{|c|c|c|c|c|}
\hline Variable & $\begin{array}{c}\text { Total population } \\
(\mathrm{n}=141) \\
\end{array}$ & $\begin{array}{l}\text { Robotic surgery group } \\
(\mathrm{n}=111)\end{array}$ & $\begin{array}{l}\text { Changed surgery group } \\
(\mathbf{n}=\mathbf{3 0}) \\
\end{array}$ & $P$ value \\
\hline \multicolumn{5}{|l|}{ Pre-discharge mitral regurgitation } \\
\hline None & $66(47 \%)$ & $48(43 \%)$ & $18(60 \%)$ & \\
\hline Trivial & $70(50 \%)$ & $59(50 \%)$ & $11(37 \%)$ & .1 \\
\hline $\mathrm{I}+$ & $4(3 \%)$ & $3(3 \%)$ & 0 & \\
\hline $\mathrm{II}+$ & $2(2 \%)$ & $1(1 \%)$ & $1(3 \%)$ & \\
\hline III-IV+ & 0 & 0 & 0 & \\
\hline Pre-discharge left ventricular ejection fraction (\%) & $53 \pm 5$ & $54 \pm 5$ & $53 \pm 6$ & .9 \\
\hline Postoperative atrial fibrillation, at the time of discharge & $16(11 \%)$ & $7(6 \%)$ & $9(30 \%)$ & .001 \\
\hline Hospital length of stay (d) & $4.6 \pm 2$ & $4.2 \pm 1$ & $6.3 \pm 4$ & $<.001$ \\
\hline Documented predischarge stroke & $1(0.7 \%)$ & $1(1 \%)$ & 0 & .5 \\
\hline 30-day mortality & $1(0 \%)$ & $0(0 \%)$ & $1(0.3 \%)$ & .6 \\
\hline
\end{tabular}

Data presented as mean \pm standard deviation or no. (\%). 